\title{
Two Nations Indivisible. Mexico, the United States and the Road Ahead
}

\author{
LUIS DE LA CALLE*
}

No son pocos los libros de autores estadunidenses que intentan "explicar" qué es México y cómo se comporta. La gran mayoría parece tener como objetivo dar al lector herramientas para descifrar a un país que parece preciarse de ser expresión del surrealismo en su vida cotidiana, pero no constituye una invitación para participar, colaborar y mucho menos involucrarse con México.

Esto se debe, quizá, a que los libros son sobre México y no sobre la importancia de la nación vecina. No se estudia en aquéllos la importancia del país para Norteamérica, para Centroamérica, para América Latina y para el resto del mundo; tampoco se analiza el impacto y la relevancia para Estados Unidos mismo.

Es sintomático que, con frecuencia, los libros escritos originalmente en inglés (para un público lector estadunidense) sobre México y la relación bilateral con Estados Unidos, tengan un mayor impacto en México que en nuestro vecino del norte. Más lectores y mayor atención por parte de los objetos del estudio que de los sujetos a los que están, en principio, dirigidos. Un fenómeno similar acontece en el ámbito noticioso: por ejemplo, una audiencia crítica sobre algún aspecto mexicano en el Congreso de Estados Unidos se reportará en México en primeras planas de los diarios más importantes y se atribuirá a Estados Unidos la conclusión a que llegue el subcomité o comité respectivo, independientemente de su importancia. Del otro lado de la frontera, donde la audiencia de hecho ocurrió, lo más probable es que el suceso pase por completo inadvertido.

La asimetría de la relación bilateral se refleja, así, en lo que se escribe y reporta sobre México. Para Estados Unidos, el vecino del sur es uno

\footnotetext{
* Participante en las negociaciones que llevaron a la firma del TLCAN. ldelacalle@cmmsc. com.mx
} 
$\mathrm{O}^{\prime}$ Neil utiliza el mismo argumento de que a Estados Unidos le conviene que a México le vaya bien; pero va más allá: propone que son dos naciones indivisibles $[. .$.$] ,$ comparten un mismo devenir. más; para el país "indispensable", los demás no lo son. Históricamente, México ha contado para poco. Por esta razón, la única manera de ser tomado en cuenta en Washington ha sido por medio de la insistencia y la persuasión. Por tal razón, no es descabellada la idea de no pocos de que es mejor no estar en el radar de las prioridades de Estados Unidos.

Shannon K. O’Neil quiere convencer a los estadunidenses de que México importa. No tanto en sí mismo, sino para Estados Unidos. Aunque esto pareciera obvio, no lo es.

El proceso de aprobación del Tratado de Libre Comercio de América del Norte (TLCAN) fue mucho más complicado de lo que se esperaba, en vista de la apertura que significaría. Estados Unidos tenía, en el momento de la negociación, un arancel promedio del 4 por ciento para productos provenientes de México y relativamente pocas restricciones en materia de inversión y servicios. En cambio, México tenía una economía menos abierta, lo que representaba un mayor esfuerzo de ajuste ante la apertura ambiciosa que planteaba el Tratado de Libre Comercio de América del Norte.

Así, la estridencia del debate para la aprobación del TLCAN no sólo se relacionaba con la apertura que Estados Unidos ponía en la mesa, sino con las dudas que implicaba asociarse con un país no desarrollado (de hecho, era el primer voto no eurocéntrico de su Congreso en el ámbito económico en la historia). A pesar de lo evidente, Canadá y México son sus vecinos, no fue fácil convencerse de que era natural asociarse con ellos. Con Canadá, sí, pero ¿por qué México? La única manera, justificada por supuesto, era argumentar que el TLCAN era benéfico para Estados Unidos, igual que la única manera de considerarlo aceptable en México era que le resultaba favorable; es decir, que la mayor integración económica entre ambos vecinos fuese buena para ambos.

O'Neil utiliza el mismo argumento -no por obvio ya aceptado- de que a Estados Unidos le conviene que a México le vaya bien; pero incluso va más allá: propone que son dos naciones indivisibles. No en el sentido de que comparten una frontera y, por ende, no pueden separarse, sino que comparten un mismo devenir. Un argumento difícil de sostener, tanto en México como en Estados Unidos. Del lado mexicano, tener un futuro común pareciera implicar una pérdida de soberanía; del otro lado, lo es aún más.

Un país indispensable no puede verse como parte indivisible de otra nación. Sin embargo, al escoger el título, Two Nations Indivisible, la autora apeló al sentimiento de nacionalidad más profundo de los estadunidenses. 
Para argumentarlo, empieza hablando del México "real", en el sentido de diferente de lo que se lee, escucha y se ve en los medios de comunicación y la percepción prevaleciente:

I see a sharp contrast between what I read and hear in the United States about our southern neighbor and what I experience on Mexico's streets. Mexico faces serious challenges, but it is also committed to addressing them, working to enlarge its middle class, open its political system, and provide for its citizens" (xix).

Al tiempo que sentencia que "the United States' future will be highly influenced by these outcomes next door [...]. The stakes for the U.S. economic growth, social cohesion, and basic security are high" (xix). No obstante, O'Neil argumenta que la política pública de su país no ha evolucionado para entender e incorporar esta nueva realidad.

México ya no representa sólo un error de redondeo para el comportamiento de la economía de Estados Unidos (compra el 14 por ciento de sus exportaciones), los mexicoamericanos tienen un creciente peso político, económico y social en ambos países, mientras que el país se ha vuelto un importante actor en el ámbito mundial (en el G-20 y en las negociaciones comerciales internacionales, por ejemplo).

Como muchos otros especialistas, la autora considera que México se halla en una encrucijada decisiva que lo llevará al desarrollo o al desorden. Para capturar el potencial, O'Neil propone a sus lectores imaginar el beneficio de que Estados Unidos tuviera a España como vecino, pero al mismo tiempo advierte que "traces of growing disorder are there" (5). De hecho, percibe a México como la prueba más importante (no tanto el Medio Oriente, como ha insistido el Council on Foreign Relations, al que pertenece) de consolidación de la democracia sustentada por una economía de mercado. Si México no triunfa -señala-, las consecuencias para la política exterior de Estados Unidos serían desastrosas, pero más aún para su bienestar económico, social y político en el ámbito interno. Y llega más lejos al sugerir que el énfasis de la política exterior de su país en el Medio Oriente ha sido un distractor sobre lo realmente importante: México.

Ésa es una contribución del libro, especialmente viniendo de una autora ligada al mundo de la diplomacia: la importancia real de México radica en su impacto para Estados Unidos. Una manera burocrática de
La autora considera que México se halla en una encrucijada decisiva que lo llevará al desarrollo o al desorden [...], la importancia real de México radica en su impacto para Estados Unidos. 
Este libro traza una ruta para que el ciudadano estadunidense, no sólo el de Washington, D.C., o el de Nueva York, entienda los retos y oportunidades para y con México, así como que pueda atender el "desafío más ignorado e importante de la política exterior de Estados Unidos". describirlo sería decir que en la relación bilateral importan mucho más el Departamento del Tesoro, de Comercio, de Agricultura, de Seguridad Nacional, los reguladores económicos y sus contrapartes que el Departamento de Estado y la Cancillería de México.

Este libro traza una ruta para que el ciudadano estadunidense, no sólo el de Washington, D.C., o el de Nueva York, entienda los retos y oportunidades para y con México, así como que pueda atender el "desafío más ignorado e importante de la política exterior de Estados Unidos" (10).

Aunque este volumen también reconoce que la ruta que escoja México depende de los mexicanos, Estados Unidos (por acción o inacción) apoyaría u obstaculizaría ese proceso de modernización. El punto central de este trabajo es que el resultado tendría sustanciales repercusiones en Estados Unidos. En ese sentido, resulta novedoso y valioso en lo que se dice.

Shannon K. O’Neil dedica un capítulo entero a resumir las relaciones diplomáticas bilaterales, desde Poinsett (sin reconocer la etimología de Noche Buena en inglés y francés) hasta Pascual; otro más a la importancia de la emigración para México y la inmigración para Estados Unidos, así como a su efecto para unir a ambos países (volverlos indivisibles) y respecto de las dificultades y oportunidades de la frontera. El siguiente capítulo se aboca al solitario peregrinar democrático de México, "una democracia vibrante, pero imperfecta" (10); otro más a sorprender a los lectores estadunidenses sobre el hecho de que México se está convirtiendo en un país de clase media y ya no pobre; uno más a describir el empeoramiento de la seguridad en México (en parte por el avance democrático), el obstáculo de la ausencia del Estado de derecho para el desarrollo, el crecimiento y la justicia, así como el reto de instaurar el imperio de la ley, pero subrayando el papel de Estados Unidos como proveedor de un mercado infinito de drogas, armas y dinero corruptores. El último capítulo versa sobre la necesidad de decidir respecto del futuro común, con una sociedad basada en la gente, en la competitividad compartida, en la seguridad y la democracia.

El epílogo de este trabajo es una reflexión sobre el regreso del PRI a Los Pinos y el impacto que tendrá en México y en la relación bilateral. La clave residiría en profundizar la democracia y avanzar en el más grande reto para México: la inclusión social.

Como se dijo al inicio de esta nota, la selección del título del libro revela la intención de Shannon K. O’Neil: Two Nations Indivisible parafrasea 
el "Juramento de lealtad"1 que los ciudadanos de Estados Unidos proclaman en ocasiones solemnes. Así, desde el título, pone en el centro de su libro la tesis central: México es importante para Estados Unidos. No obstante, en todo el libro se encuentran otras frases bien logradas que podría haber escogido como título de esta obra, pero se inclinó por la de mayor resonancia entre el público de su país, entre las que se encuentran las siguientes:

- Salsa outsells ketchup (45)

- Unfounded fears (47)

- Lost in the headlines, Mexico's real story today (155)

- Mexico stands at a crossroad (156)

- U.S.-Mexico relations should start with people (156)

- A180-degree turn from current policy (158)

- United States and Mexico have yet to talk honestly (165)

- A Spain for the Americas (167)

- Much to lose, but much more to gain (175).

\section{Biblografía}

O'Neil, Shannon K.

2013 Two Nations Indivisible. Mexico, the United States and the Road Ahead. Oxford University Press.

1 "I pledge allegiance to the flag of the United States of America and to the Republic for which it stands, one nation under God, indivisible, with Liberty and Justice for all" (las cursivas son mías). 